The final publication is available at Elsevier via: http://dx.doi.org/10.1016/j.apenergy.2016.09.086 @) 2016. This manuscript version is made available under the CC-BY-NC-ND 4.0 license http://creativecommons.org/licenses/by-nc-nd/4.0/

\title{
Optimal Energy-efficient Predictive Controllers in Automotive Air-conditioning/Refrigeration Systems
}

\author{
Yanjun Huang ${ }^{\mathrm{a}, *}$, Amir Khajepour ${ }^{\mathrm{a}}$, Farshid Bagheri ${ }^{\mathrm{b}}$, Majid Bahrami ${ }^{\mathrm{b}}$ \\ ${ }^{a}$ Department of Mechanical and Mechatronics Engineering, University of Waterloo, Ontario, N2L3G1, Canada; \\ ${ }^{b}$ School of mechatronic system engineering, Simon Fraser university, Surry, BC, V3T OA3, Canada
}

Abstract - This paper presents several robust model predictive controllers that improve the temperature performance and minimize energy consumption in an automotive air-conditioning/refrigeration (A/C-R) system with a three-speed and continuously-varying compressor. First, a simplified control-oriented model of the A/C-R system is briefly introduced. Accordingly, a discrete Model Predictive Controller (MPC) is designed based on the proposed model for an A/C-R system with a three-speed compressor. A proper terminal weight is chosen to guarantee its robustness under both regular and frost conditions. A case study is conducted under various heating load conditions. Two hybrid controllers are made, which combine the advantages of both the on/off controller and discrete MPC such that they will be more efficient under any ambient heating condition. In addition, a continuous MPC is developed for systems with continuous variable components. Finally, the experimental and simulation results of the new controllers and the conventional on/off controller are provided and compared to show that the proposed controllers can save up to $23 \%$ more energy.

Index Terms: Air-conditioning/Refrigeration systems; Frosting; Discrete MPC; Robust MPC; Hybrid controller

\section{Nomenclature}

\begin{tabular}{|c|c|c|c|}
\hline$A_{v}$ & opening area of expansion valve & $N_{\text {cond }}$ & condenser fan control input \\
\hline$A_{c}\left(A_{e}\right)$ & cross-sectional area of condenser (evaporator) tube & $N_{\text {evap }}$ & evaporator fan control input \\
\hline$A_{o c}\left(A_{o e}\right)$ & exterior area of the condenser (evaporator) & $P_{c}\left(P_{e}\right)$ & pressure of two heat exchangers \\
\hline$\alpha_{i c}\left(\alpha_{i e}\right)$ & $\begin{array}{l}\text { equivalent refrigerant-side heat transfer coefficient in } \\
\text { two-phase region }\end{array}$ & $\rho_{v}$ & density of refrigerant through the valve \\
\hline$\alpha_{o c}\left(\alpha_{o e}\right)$ & air-side heat transfer coefficient & $\rho_{\text {ref }}$ & density of refrigerant \\
\hline$\alpha_{i c s h}\left(\alpha_{i e s h}\right)$ & refrigerant-side heat transfer coefficient in superheat region & $\rho_{l c}\left(\rho_{l e}\right)$ & density of liquid refrigerant \\
\hline$C_{p}$ & specific heat of the heat exchangers & $\rho_{g c}\left(\rho_{g e}\right)$ & density of vapor refrigerant \\
\hline$C_{v}$ & discharge coefficient of expansion valve & $\rho_{\text {shc }}\left(\rho_{\text {she }}\right)$ & density of refrigerant in superheat section \\
\hline$C_{\text {air }}$ & specific heat of the ambient air & $T_{a m b}$ & ambient temperature \\
\hline$D_{i c}\left(D_{i e}\right)$ & heat exchanger tube internal diameter & $T_{w f c}\left(T_{w f e}\right)$ & equivalent temperature of tube wall \& fin \\
\hline$h_{g e}\left(h_{g c}\right)$ & enthalpy of vapor refrigerant & $T_{r c}\left(T_{r e}\right)$ & saturation temperature of refrigerant \\
\hline$h_{i c}\left(h_{i e}\right)$ & enthalpy of refrigerant at the inlet of heat exchanger & $T_{a c}\left(T_{a e}\right)$ & air temperature around the heat exchanger \\
\hline$h_{i s}$ & isentropic of refrigerant in compressor & $T_{s h}$ & superheat \\
\hline$h_{l c}\left(h_{l e}\right)$ & enthalpy of liquid refrigerant & $T_{i c}$ & refrigerant temperature at the inlet of condenser \\
\hline$h_{l g c}\left(h_{l g e}\right)$ & latent enthalpy of refrigerant & $T_{c \text { argo }}$ & temperature of cargo \\
\hline
\end{tabular}




\begin{tabular}{llll}
\hline \hline$h_{o c}$ & enthalpy at the outlet of condenser & $T_{\text {cargo_init }}$ & initial temperature of cargo \\
$l_{c}\left(l_{e}\right)$ & length of two-phase section in two heat exchangers & $V_{d}$ & volumetric displacement of compressor \\
$\dot{m}_{v}$ & refrigerant mass flow rate through the expansion valve & $\eta_{\text {vol }}$ & volumetric efficiency of compressor \\
$\dot{m}_{\text {comp }}$ & refrigerant mass flow rate through the compressor & $\eta_{a}$ & adiabatic efficiency of compressor \\
$m_{\text {pipe }}$ & total refrigerant mass in the pipes & $\bar{\gamma}_{c}\left(\bar{\gamma}_{e}\right)$ & mean void fraction of two-phase section \\
$m$ & heat exchanger total mass & $N$ & prediction and control horizontal length \\
$N_{\text {comp }}$ & compressor speed & $P, \mathfrak{Q}$ & weight factor \\
\hline \hline
\end{tabular}

\section{INTRODUCTION}

The continuously increasing demands on energy conservation and environmental protection have driven researchers to develop more efficient and "green" vehicles [1] [2]. Recently, A/C-R systems have been widely used as the main auxiliary devices in vehicles. For example, A/C-R systems in food delivery trucks consume up to $25 \%$ of the vehicle's total fuel consumption. Efficiently operating A/C-R systems can significantly improve operating costs and the vehicle's effects on the environment [3] [4]. Thus, making more efficient auxiliary devices such as A/C-R systems can bring many benefits to vehicle owners as well as the environment [5]. For any A/C-R system, a foremost step in achieving better performance and higher energy efficiency is a proper control strategy. However, in most conventional vehicles, the compressor speed is proportional to the engine speed instead of actively varying with the requirements of passengers or working conditions. This impedes the development of advanced controllers for A/C-R systems given that the controllers are usually applied to manipulate the speeds of the compressor and fans of heat exchangers. Recently, the onboard energy storage system (ESS) of anti-idling systems [6], hybrid electric vehicles (HEVs) [7] and electric vehicles (EV) [8] [9] is capable of powering the A/C-R system independently such that the A/C-R system can be disconnected from the engines [10]. This indicates the feasibility of the electrification of the A/C-R system and the subsequent application of advanced controllers in vehicles. For the sake of accurate prediction, an accurate yet simple dynamic model of the whole A/C-R system is a prerequisite for the design of any advanced controller. A simplified control-based model for all-purpose A/C-R systems that is validated by experimental data is provided [11]. Further based on the model, the controllers' development process is presented and followed by experimental validation and comparison work.

A literature review on the existing controllers including the MPC of A/C-R systems and the novelties of this paper is presented in the second section; next, the simplified model is briefly introduced. A brief introduction of the experimental system is provided in the following section. In addition, the development and implementation process of controllers are elaborated upon. Furthermore, the experimental results of both the discrete MPC and the conventional on/off controller are provided to demonstrate the energy-saving ability and the robustness of the proposed MPC. Moreover, a case study under varying heating load conditions is conducted by proposing the hybrid MPCs and the continuous MPC. In the last section, comments and future work are discussed. 
The A/C-R system generally consists of four main components: the compressor, evaporator, expansion valve, and the condenser, as shown in Fig. 1. One cycle is taken as an example for the demonstration of the whole working process of the A/C-R system. Let us begin with the high-pressure and low-temperature liquid refrigerant after it exits the condenser. It stays in the liquid phase before entering the expansion valve. Since the valve is usually assumed to be adiabatic, the enthalpy of the refrigerant at the inlet and outlet of the valve should be equal. In the evaporator, the low temperature and low-pressure two-phase refrigerant absorbs heat from the cargo space and exits from the superheat $(\mathrm{SH})$ section in gas form to avoid damaging the compressor. The gas refrigerant is pressed when going through the compressor and exits the compressor with high temperature and high pressure. Finally, when it reaches the condenser, the superheated and over pressured gas refrigerant will go through the SH, two-phase and subcooling (SC) section when flowing through the condenser. Due to the extensive applications of A/C-R systems in different areas, many controllers have been developed in the literature.

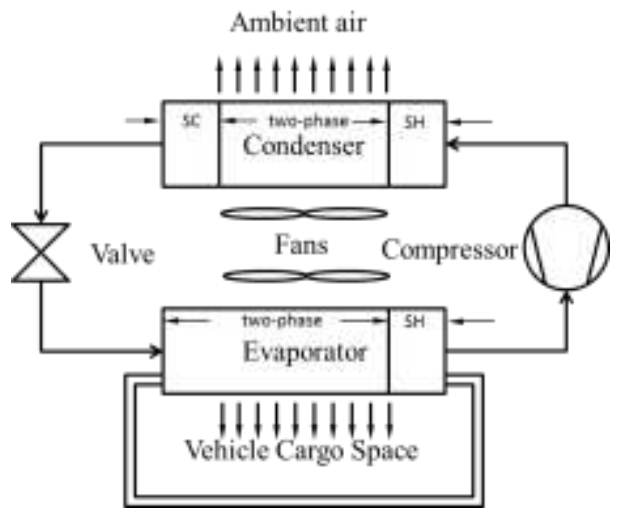

Fig. 1 Schematic diagram of an automotive A/C-R system with cargo

Thanks to its simplicity, the on/off controller was initially applied. It could maintain the required temperature in a certain range by turning the whole system on or off. Instead, the on/off controller has many limitations. First, it is unable to regulate the temperature oscillation amplitudes in changing conditions including changing ambient temperatures or varying food temperatures. Secondly, frequent compressor activations (turning it on/off) can lead to excessive power consumption and cause the mechanical components to wear down over time. Above all, energy efficiency is not considered at all, and that is why [12] and [13] improved the original on/off controller's efficiency by introducing adaptive or optimization algorithms. However, due to the nature of the on/off controller, it is impossible to greatly enhance its performance. Recently, the application of variable-speed components into the A/C-R system makes the development of more efficient controllers possible. Particularly, as anti-idling technologies and electric vehicles become more popular, the electrification technology of the A/C-R system in the vehicle will separate the compressor from the engine, which could make compressor actively change its speed instead of passively following the engine's speed. The current controllers (other than the on/off one of the A/C-R system) can be classified into three types [14]: classic feedback controller, intelligent controller, and advanced controller. As the most popular type of conventional feedback controllers, the PID controller 
has been used for a long time. A relevant example is the superheat-expansion valve and temperature-compressor control [15]. That means the superheat will be controlled by the expansion valve, and the temperature will be controlled by the compressor via two separate PID controllers. Nevertheless, due to the nonlinear and MIMO nature of an A/C-R system, it is difficult to find and tune the controller parameters [16]. A strategy used to decouple the controllers was developed in [17]. Still, this conventional PID controller does not directly consider saving energy.

Artificial intelligent control approaches, such as artificial neural network (ANN) control, fuzzy logic control, and the expert system, etc., are utilized to deal with nonlinearities or uncertainties in A/C-R processes. ANN has a strong modeling capability for nonlinearities; whereas, fuzzy logic can deal with uncertainties in a straightforward manner. Besides being used directly as controllers based on their own formulation characteristics, ANN, fuzzy logic, etc., also perform the roles of A/C-R models [18], computing methods, and approximations of other control algorithms. In some cases, these artificial intelligent control approaches are combined with the A/C-R system control [14]. However, their limitations were discussed in [19], which comprise over training, extrapolation, network optimization, and the lack of optimal controls. These drawbacks impede its development and application.

Advanced control generally includes robust control (e.g. Sliding Model Control), adaptive control, optimal control (such as the MPC), and so on. A second-order Sliding Mode Controller (SMC) for the SISO refrigeration system was presented in [20], which regulates the refrigerant's relative length in the evaporator by manipulating the compressor speed. This controller can also effectively alleviate chattering phenomenon, but it does not deal with power consumption directly. A multivariable adaptive controller was proposed in [21], which is able to identify different linear models for a nonlinear system over the domain of operating conditions. There are also other classes of nonlinearity compensation controls like robust control [22], gain scheduling LQR [23] [24] and optimizing control [25].

In all of these advanced control methods, the MPC is a more successful and promising control algorithm based on studies of model identification, optimized algorithm, control structure analysis, parameter tuning, and relevant stability and robustness. In A/C-R system control, the MPC is gradually becoming a major control method. The main value of the MPC is its ability to control multivariable systems under various constraints, especially slow dynamic plants, in an optimal way. It can simultaneously control more than one objective to achieve multi-objective and multivariable control; these variables include air temperature, relative humidity, the decrease of operation cost (e.g. energy saving), the improvement of air quality, and enhancement of steady-state performance and robustness. A comprehensive literature review was conducted in [16] on the theory and applications of controllers. In particular, they focused on the MPC in the HVAC systems of buildings, and they elaborated upon the factors that influence the performance of the MPC such as controller structure, process type, optimization algorithms, plant model, prediction horizon, control horizon, constraints, and an objective function. A Takagi-Sugeno fuzzy model was used to represent the highly nonlinear HVAC system in temperature predictive control. In order to reduce the computational effort of the non-convex optimization 
89 problem, a combination of a branch-and-bound search technique was used [26]. A hierarchical multiple MPC was proposed for the

temperature control of the HVAC system based on a Takagi-Sugeno fuzzy model [27]. Authors in [28] have applied a neuro-predictive controller for the temperature control of automotive air conditioning systems. However, the conclusions are tenuous without any supporting experimental work. Literature [29] designed a MPC for a multi-evaporator vapor compression cooling cycle. A decentralized control structure was employed where the global MPC was to find the set points of the required cooling as well as evaporator pressures and local PI controllers were used for set-point tracking. By properly controlling evaporator pressures and superheat, energy efficiency can be improved. Authors in [30] used a neuro-fuzzy network based offline optimization to approximate the input-output relationship of a robust MPC, and validated it on an air-handling unit for the temperature control to increase the computational efficiency of a nonlinear robust MPC. An exergy-based objective function was incorporated into a nonlinear MPC to improve the coefficient of performance (COP) of a vapor-compressor cycle operation [31]. Due to the nonlinear objective function, the "fmincon" command in MATLAB that was used for the simulation and real-time implementation is not feasible in practice due to its high computational time. J. Ma et al. proposed an economic MPC to reduce costs for building HVAC systems. In each time interval, a min-max optimization technique is used and transferred to a linear programming problem instead of solving the optimization problem directly; this technique minimizes electricity costs and finds the optimal input for the next step [32]. In [33], the author adopted a complex nonlinear model of a vapor compressor system derived by [23], linearized it and subsequently designed a MPC to control the evaporator pressure and superheat by manipulating the compressor speed and electronic expansion valve. The purpose of this MPC was to improve the energy efficiency of the overall plant. In order to show its performance in real situations, several scenarios were simulated by using the linearized mode, but this was done without any experimental validation. In addition, the effects of model inaccuracy on the controller were not studied. An MPC was designed for a commercial multi-zone refrigeration system to minimize the total energy consumption, which employed a fast convex quadratic programming solver to solve a sequential convex optimization problem so as to handle the non-convexity of the objective function. In order to limit the size of the optimization problem in each step, a sample time of 15 mins was chosen for predictions of the next 24 hours [34]. A low-complexity MPC was developed for building cooling systems with thermal energy storage. In order to improve the computational efficiency, a periodic moving window blocking strategy is utilized [35]. A time-varying periodic robust invariant set discussed in [36] was used as the terminal constraint to guarantee the robustness under the time-varying uncertain cooling demand. The running time for each step was about 20mins, which satisfies the sample time of $1 \mathrm{~h}$ chosen for the MPC for prediction of the next 24 hours. A learning-based MPC was proposed in [37] to minimize the energy consumption of an air conditioner while it maintains a comfortable temperature at the same time. A statistical method and a mathematical model for the temperature dynamics of a room were used to learn about the time-varying heating load caused by occupants and equipment. Based on the information learned from the heating load, this MPC will determine the state (on/off) of the air conditioner. Ultimately, it is 
still a two position controller for the air conditioner, but it is more intelligent. The authors improved their study discussed in [29]. A multi-evaporator vapor compression system was still the research target and the global MPC was used to find the required cooling and pressure set points for each zone. The local MPCs and PIDs for each evaporator were used to track these set points by manipulating the valve position and evaporator fan speed. Energy efficiency was guaranteed by choosing the proper pressures and superheats instead of directly integrating the system's inputs into the objective functions of the MPC [38]. An adaptive MPC for a reefer container was proposed in [39]. Model parameters, states as well as the ambient temperature information for the next 24 hours were identified online. This long prediction period required a relatively long time interval of 1 hour to reduce the optimization problem size at each time step so as to guarantee the real-time application. Since the MPC is recalculated once every hour, the cooling provided by the refrigeration system could be incorrect for up to one hour. This MPC is not suitable for reefer containers in delivery trucks with small thermal inertia since such trucks unload their goods regularly resulting in some extra heating load in the container, which can ruin the quality of the goods. Due to the small thermal inertia and subsequent fast thermal dynamics, the 1 hour time interval is too large to be used.

Compared to the aforementioned literature, the differences of this paper are as follows: 1) from the application point of view, this paper proposes a robust real-time MPC controller for automotive A/C-R systems. Most of the MPC applications of A/C-R systems in the existing literature are designed for buildings rather than for vehicles because the compressor, the most energy-consuming component in the A/C-R system, is directly connected to engine in conventional vehicles. The fact that its speed cannot be freely changed impedes the applications of advanced controllers. As HEVs, EVs, and anti-idling techniques become more popular, the electrification of the A/C-R systems and application of the MPC is possible. In addition, buildings with large thermal inertia present extremely slow temperature dynamics in which time intervals in minutes or even hours [16] [35][37][38][39] are used in the controller loops. Vehicles with small passenger compartment, relatively poor insulation conditions reflect a relatively fast thermal dynamics, which calls for a smaller time interval, so controllers with real-time implementation potential are required. Our work in this paper introduces an MPC for A/C-R systems that satisfies the requirements for vehicle applications. 2) Regarding the model used for MPC development, neither the intelligent artificial $[26][27][28][30]$ nor the data-driven modeling method is utilized. In this paper, the boundary-moving and lumped parameter method [22] [23] is adopted according to the physical structure and characteristics of the plant. This method does not need any training work. Using an online parameter identification algorithm, the proposed model is sufficient to guarantee a better prediction accuracy required by the MPC over the models used in the literature. In addition, as opposed to complex models with more than fifteen states developed in the literature [13][22][23], this paper uses a simplified six-state control-oriented model with comparable accuracy. This has been done by introducing the effects of fins and superheat sections in the model 
148 [11]. 3) In terms of the controller itself, due to the discrete nature of the constraints in many A/C-R systems [25] [40] [41] [42]

149 a discrete MPC is proposed, which is rarely mentioned in the current literature about A/C-R systems. Thanks to the simple 150 model, this controller is fast enough to be applied in real time. The design process of this discrete MPC can serve as a 151 framework for other similar applications with several discrete points. Furthermore, the hybrid controllers combine the 152 advantages of both the MPC and the on/off controller to make more efficient controllers under any heating load condition.

153 Above all, concerning the robustness of the proposed MPC, as is suggested by [43] [44] a relatively large terminal weight is 154 experimentally tested and chosen for the sake of robustness. The control performance is studied under both large external 155 disturbances and situations of model parameter uncertainties. A 200-second heating load - up to $23 \%$ of the original heating 156 load as the external disturbance is applied to the system to evaluate the robustness of the controller. Frosting, a common 157 phenomenon in A/C-R systems, can lead to model inaccuracy, or even violate the assumptions of the modelling. However, 158 even under such harsh situations, the control system shows an excellent performance because of the robustness of the 159 proposed controller; whereas, the existing literature seldom shows the performance of controllers during the frosting period of the A/C-R system.

162 The development of advanced controllers is usually based on a dynamic model, which should be simple enough for real-time applications and reflect the main dynamics of the plant. In this section, the dominant equations of the four main components of the A/C-R system are provided and explained, for more detailed information please the previous work [11].

\section{A. Expansion Valve}

The expansion valve is assumed to be isenthalpic i.e. the enthalpy at the inlet of the valve is identical to that at the outlet. No matter which kind of expansion valve, the refrigerant mass flow rate $\dot{m}_{v}$ through the expansion valve is modeled by:

$$
\dot{m}_{v}=C_{v} A_{v} \sqrt{\rho_{v}\left(P_{c}-P_{e}\right)}
$$
by experimental data [45][46] $P_{c}$ and $P_{e}$ are the pressure of condenser and evaporator, respectively.

\section{B. Compressor model}

The dynamics of the compressor can be demonstrated by:

$$
\begin{gathered}
\dot{m}_{\text {comp }}=N_{\text {comp }} V_{d} \eta_{v o l} \rho_{r e f}\left(P_{e}\right) \\
h_{o c}=\eta_{a}\left(h_{i s}\left(P_{e}, P_{c}\right)-h_{i c}\left(P_{e}\right)\right)+h_{i c}\left(P_{e}\right)
\end{gathered}
$$


172 Equation (2) depicts the refrigerant mass flow rate throughout the compressor with respect to the compressor speed, and Equation

173 (3) shows the enthalpy change of the refrigerant after going through the compressor.

174

175

176

177

178

\section{Evaporator}

Two common types of heat exchangers are used in the A/C-R system: the microchannel type and the fin-tube type [47]. The modeling method proposed is suitable for any type. More importantly, the modeling method takes the fins' effect into consideration and lumps it into two equivalent parameters so that the model is simple but accurate. The simplified nonlinear dynamic model of the evaporator can be written as:

$$
\begin{gathered}
h_{l g e} \rho_{l e}\left(1-\bar{\gamma}_{e}\right) A_{e} \frac{d l_{e}}{d t}=\dot{m}_{v}\left(h_{g e}-h_{i e}\right)-\alpha_{i e} \pi D_{i e} l_{e}\left(T_{w f e}-T_{r e}\right) \\
A_{e} L_{e} \frac{d \rho_{g e}}{d P_{e}} \frac{d P_{e}}{d t}=\dot{m}_{v} \frac{h_{i e}-h_{l e}}{h_{l g e}}-\dot{m}_{c o m p}+\frac{\alpha_{i e} \pi D_{i e} l_{e}\left(T_{w f e}-T_{r e}\right)}{h_{\text {lge }}} \\
\left(C_{p} m\right)_{w f e} \frac{d T_{w f e}}{d t}=\alpha_{o e} A_{o e}\left(T_{a e}-T_{w f e}\right)-\alpha_{i e} \pi D_{i e} l_{e}\left(T_{w f e}-T_{r e}\right)-\alpha_{i e s h} \pi D_{i e}\left(L_{e}-l_{e}\right)\left(T_{w f e}-T_{r e}\right)
\end{gathered}
$$

where the three states are the length $l_{e}$ of the two-phase section, the pressure $P_{e}$ of the evaporator, and equivalent temperature $T_{w f e}$ of tube wall \& fins. Equation (4) simulates the energy transfer from the refrigerant to the heat exchanger tube wall \& fins of the two-phase section [24]. Equation (5) denotes the vapor refrigerant change rate throughout the evaporator tube. Equation (6) reflects the heat conduction of the entire heat transfer process. The last term on the right-hand side represents the heat conduction throughout the superheat section, which is added to improve model accuracy and distinguish it from the model proposed in [23][24]. $\alpha_{o e}$ is regulated by the evaporator fan speed $N_{\text {evap }}$ [22].

\section{Condenser}

As is known, the total mass $m_{\text {total }}$ of the refrigerant inside the cycle is constant without considering any leakage. The mass of the refrigerant outside of the two heat exchangers is defined as $m_{\text {pipe }}$. Thus, the difference between these two masses is the mass inside evaporator and condenser, which can be shown by:

$$
m_{\text {total }}-m_{\text {pipe }}=A_{e}\left[\rho_{l e} l_{e}\left(1-\bar{\gamma}_{e}\right)+\rho_{g e} l_{e} \bar{\gamma}_{e}+\rho_{\text {she }}\left(L_{e}-l_{e}\right)\right]+A_{c}\left[\rho_{l c} l_{c}\left(1-\bar{\gamma}_{c}\right)+\rho_{g c} l_{c} \bar{\gamma}_{c}+\rho_{\text {shc }}\left(L_{c}-l_{c}\right)\right]
$$

With the same modeling method, the condenser dynamics can be represented by the following two-state model by considering Equation (7),

$$
\begin{gathered}
A_{c} L_{c} \frac{d \rho_{g c}}{d P_{c}} \frac{d P_{c}}{d t}=\dot{m}_{c o m p}-\frac{\alpha_{i c} \pi D_{i c} l_{c}\left(T_{r c}-T_{w f c}\right)}{h_{l g c}} \\
\left(C_{p} m\right)_{w f c} \frac{d T_{w f c}}{d t}=\alpha_{o c}\left(N_{c o n d}\right) A_{o c}\left(T_{a c}-T_{w f c}\right)-\alpha_{i c} \pi D_{i c} l_{c}\left(T_{w f c}-T_{r c}\right)-\alpha_{i c s h} \pi D_{i c}\left(L_{c}-l_{c}\right)\left(T_{w f c}-\left(T_{r c}+T_{i c}\right) / 2\right)
\end{gathered}
$$




\section{E. Cargo}

192

The inside temperature of the cargo is one of the control objectives, whose dynamics can be shown by the following equation:

$$
\frac{d T_{c \text { argo }}}{d t}=\frac{Q_{i n c o n v}+Q_{\text {inf }}+Q_{\text {door }}-Q_{v c c}}{(M C)_{\text {air }}}
$$

193

194

195

196

where, $\dot{Q}_{\text {inconv }}$ represents the convective heat transfer from the interior surface; $Q_{i n f}$ and $\dot{Q}_{\text {door }}$ are the load due to infiltration and opening the door respectively, and $\dot{Q}_{v c c}$ is the cooling capacity produced by the A/C-R system to balance the heating load from outside [49]. The first two loads will be treated together $\left(Q_{\text {out }}\right)$, and they can be identified by test data obtained from the previous step. $\dot{Q}_{\text {door }}$ is used as an external disturbance and added to the chamber.

By considering the boundary conditions of each component and integrating the cargo into the whole cycle, the entire model will become a six-state dynamic model. In this model, the air temperature $T_{a m b}$ at the inlet of the condenser is considered to be the ambient air temperature, and it is a measured value. The system inputs are compressor speed $N_{\text {comp }}$ as well as the frequencies ( $N_{\text {evap }}$ and $N_{\text {cond }}$ ) of two variable frequency drives (VFDs) used to manipulate the speed of the evaporator and condenser fans. The

frequencies are proportional to the two fan speeds. The six states $\left[P_{e}, P_{c}, l_{e}, T_{w f e}, T_{w f c}, T_{c a r g o}\right]$ are: pressures of the evaporator and the condenser, the two-phase section lengths, equivalent tube wall \& fins temperatures of two heat exchangers, and the temperature of the evaporator-side temperature, respectively. The output is the air temperature $T_{\text {cargo }}$ of the cargo.

\section{EXPERIMENTAL SYSTEM}

In order to validate the model and verify the performance of these new controllers, an automotive A/C-R system is built. From the schematic of the experimental system in Fig. 2, it can be seen that two independent environmental chambers are connected to the evaporator and condenser units by pipes. The evaporator-side chamber acts as the cargo and its temperature will be a controlled parameter while the temperature at the inlet of the condenser can be controlled and used as operating conditions when the experiments are conducted. 


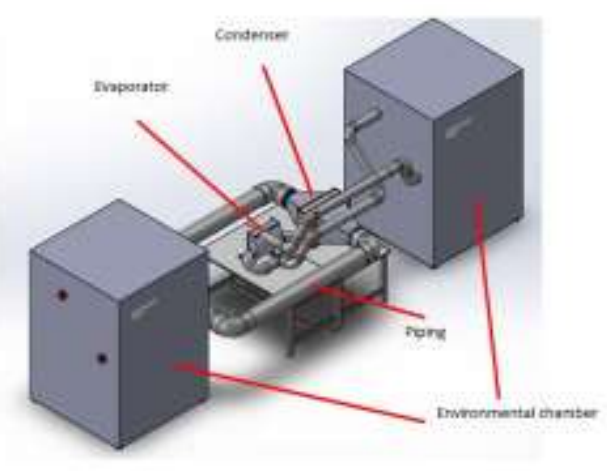

Fig. 2 Schematic of the experimental system

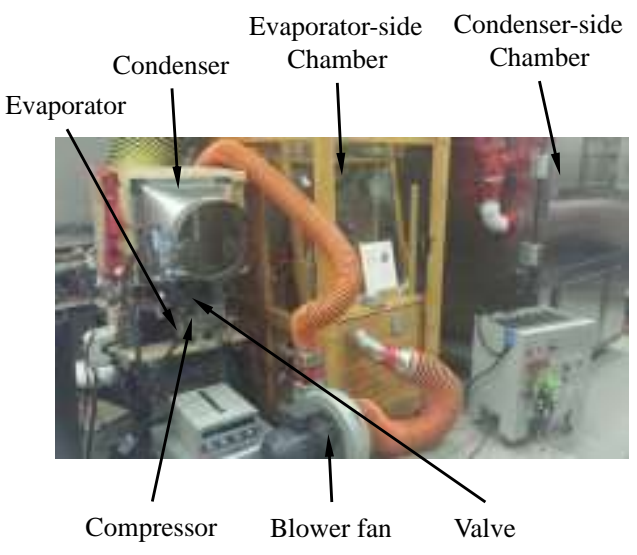

Fig. 3 Experimental system

The experimental setup is shown in Fig. 3, where the four main components of the whole system and the two chambers are

211 labeled. Fig. 4 shows one of the environmental chambers. The Micro Motion 2400S transmitter with 0.5\% accuracy from Emerson

212 Electric Co. is utilized to log the refrigerant mass flow rate, and it is located between the condenser and the thermostatic expansion

213 valve given in Fig. 5. The T-type thermocouples and pressure transducers model PX309 manufactured by OMEGA with $0.25 \%$ 214 accuracy shown in Fig. 6 are installed at four locations of the whole system to measure both the high and low 215 temperatures/pressures of the refrigerant. Fig. 7 describes T-type thermocouples and the wind sensor model MD0550 from Modern 216 Device, which are installed at eight locations on the evaporator and condenser airstreams. Also, The Data Acquisition (DAQ) 217 system is used to collect data from the thermocouples, pressure transducers, DC power supply, and flow meters, and this data is 218 sent to a computer. LABVIEW is employed to obtain all the measured data from the equipment and to save it in an EXCEL file.

219 The two fans of the evaporator and condenser are controlled by two VFDs such that the speed could be represented by frequency.

220 While the compressor only has three different speeds, an NI relay module (NI9485) is used to switch between the three discrete 221 speeds.
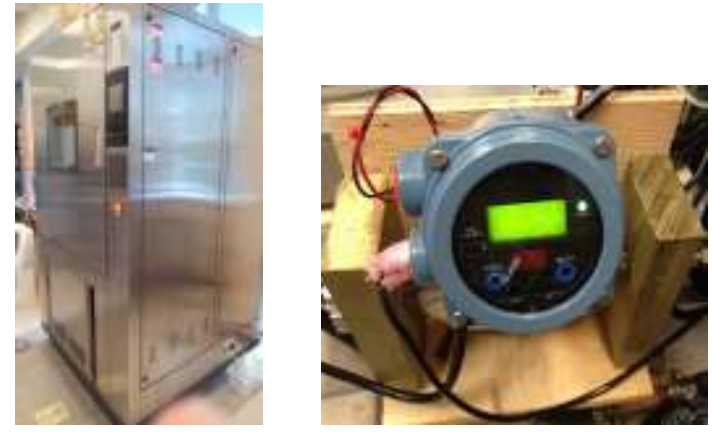

Fig. 4 Chamber
Fig. 5 Refrigerant mass flow meter

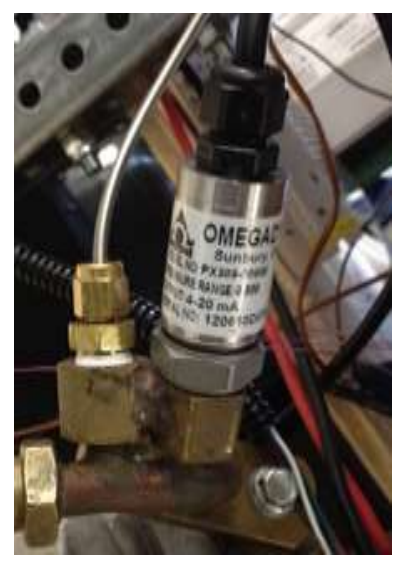

Fig. 6 Thermocouple \&pressure transducer

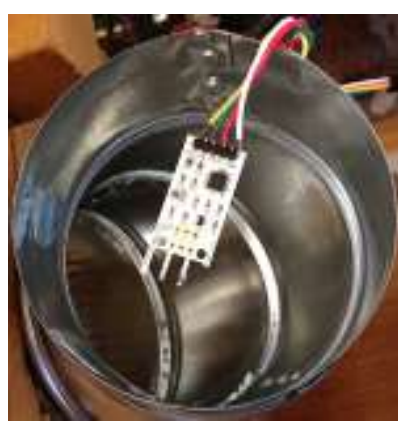

Fig. 7 Air temperature\&velocity sensors 


\section{A. On/off controller}

The on/off controller is most commonly used in vapor compression units because of its simplicity. However, it has many drawbacks as mentioned in the previous sections. Therefore, the on/off controller developed in this section serves simply as a basis of comparison for new controllers. The on/off control strategy is actually a simple hysteresis where the hysteresis band is used to reduce the compressor's frequent switching. When the system is on, the compressor is running at maximum speed. The controller is driven by the error signal between the measured temperature and the temperature set point in the cargo space [49].

The controller was built in MATLAB/SIMULINK and LABVIEW for simulation and experiment, respectively. Due to the slow dynamics of the A/C-R system, the control \& simulation loop is employed in the control design \& simulation module instead of the real-time module; whereas, the simulation time, step size, and timing source are set up to guarantee that the controllers run in real time.

\section{B. $M P C$}

As an optimal control method, the MPC originated in the chemistry industry's control techniques. It is characterized by its slow dynamics, which provides enough time for optimization calculations [50]. As is known, the A/C-R system is a highly nonlinear MIMO system with slow dynamics making it suitable for MPC application. In general, three parts are included in an MPC: a predictive model that aims to predict future behavior of the process, a receding horizon optimization algorithm that will solve an explicit optimization problem formulated into several future sampling periods, and feedback correction to keep the controlled variables at the set points and enhance the robustness of the A/C-R control system [51].

Using a highly complex nonlinear model for the development of a model predictive controller, the computational efficiency will be extremely low, so its real-time implementation will become expensive or even unrealistic for industrial applications. To solve this problem, a linear MPC will be developed in this paper. After linearizing and discretizing the nonlinear model [52], a finite horizon optimization problem [53] is formulated at each time interval. The objective function is shown below,

$$
J\left(x_{0}, u_{0}\right)=e(N)^{T} P e(N)+\sum_{k=0}^{N-1}\left[e(k)^{T} Q e(k)+u(k)^{T} R u(k)+\Delta u(k)^{T} S \Delta u(k)\right]
$$

s.t.

$$
\begin{gathered}
x_{\min } \leq x(k) \leq x_{\max }, \quad k=0, \ldots N-1 \\
u_{\min } \leq u(k) \leq u_{\max }, \quad k=0, \ldots N-1 \\
\Delta u_{\min } \leq \Delta u(k) \leq \Delta u_{\max }, \quad k=0, \ldots N-1
\end{gathered}
$$

where, $e$ is the tracking error of the temperature; the first term on the right-hand side is the terminal cost; the second term is stage cost; the third term represents control effort cost and the last term is control input rate costs. $P, \mathbb{Q} R$ and $S$ are weights to balance 
each term. The objective function is transferred into a quadratic form with respect to the increment of control inputs. As the prediction horizon length is $N$, the deviation trajectory of future states will be obtained by the discrete model:

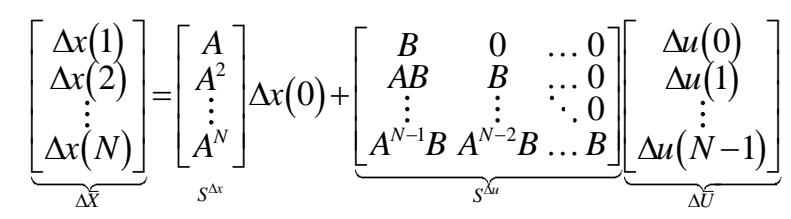

Then, the deviation of the future outputs can be rewritten into a compact form by:

$$
\underbrace{\left[\begin{array}{c}
\Delta y(1) \\
\Delta y(2) \\
\vdots \\
\Delta y(N)
\end{array}\right]}_{\Delta \bar{Y}}=\underbrace{\left[\begin{array}{cccc}
C & 0 & 0 & 0 \\
0 & C & 0 & 0 \\
0 & 0 & \ddots & 0 \\
0 & 0 & 0 & C
\end{array}\right]}_{C^{x}} \Delta \bar{X}
$$

The convex quadratic objective function only with respect to the increment of inputs will be obtained by inserting Equation (13) into the original objective function shown in Equation (11) and neglecting the constant term:

$$
\begin{gathered}
J\left(x_{0}, u_{0}\right)=\frac{1}{2} \Delta \bar{U}^{T} H \Delta \bar{U}+\Delta \bar{U}^{T} g \\
H=2\left(C^{\Delta X} S^{\Delta U}\right)^{T} \bar{Q}\left(C^{\Delta X} S^{\Delta U}\right)+\bar{R}+\bar{S}, \quad g=2\left(C^{\Delta x} S^{\Delta u}\right)^{T} \bar{Q}\left(C^{\Delta x} S^{\Delta u}-\bar{Y}_{r e f}\right)
\end{gathered}
$$

s.t.

$$
\begin{aligned}
& \Delta \bar{U} \geq \max \left(\Delta \bar{U}_{\text {min }}(U), \lambda \bar{U}_{\text {min }}(\Delta \bar{U}) \Delta \bar{U}_{\text {min }}(X)\right) \\
& \Delta \bar{U} \leq \min \left(\Delta \bar{U}_{\text {max }}(U), \Delta \bar{U}_{\text {max }}(\Delta \bar{U}) \Delta \bar{U}_{\text {max }}(X)\right)
\end{aligned}
$$

where the Hessian matrix $(H)$ is symmetric and positive or semi-positive definite and $g$ is the gradient vector. $\bar{Q}, \bar{R} \overline{\mathcal{S}}$ and $\bar{Y}$ ref should be reformulated according to the prediction horizon length $N$ based on $Q, R S$ and $Y_{\text {ref }}$. The updated constraints of the increment of the control can be found by the reformulation of Equation (12) and the constraints shown in Equation (11). For example, the constraints of the states can be applied to $\Delta \bar{U}$ as $\Delta \bar{U}_{\max }(X)$ by Equation (12). Since the optimal result is the small variation $\Delta \bar{U}$, the real optimal $\bar{U}$ can be obtained by adding the initial input $U_{0}$. The first element of the optimal solution will be applied to the real system.

This linear MPC is implemented into MATLAB/SIMULINK and LabVIEW for simulation and experiment, respectively. The detailed structure of the MPC in the Control \& Simulation Loop in LABVIEW is depicted in Fig. 8. First, the thermodynamic properties, such as density, enthalpy, and entropy, of the refrigerant under the current working conditions are obtained online by feeding the fresh measurements into lookup tables followed by parameter and state identification, where some unknown parameters and states are identified online. Then, all the known information is sent to the MPC algorithm, whose output is a quadratic problem (QP), shown in Equation (14). A QP open source solver [54], which is originally written in C, is also integrated into the Control \& Simulation Loop in LABVIEW and solves the QP at each time interval. The outputs will be delivered to the evaporator and condenser fans as well as the compressor pump via some other NI DAQs control modules to regulate their speeds. 
If the three control inputs are continuously varying in their ranges, the MPC is the continuous one. Due to the discrete constraint of the compressor speed (i.e. low, medium and high speed), the discrete MPC is designed, where three continuous MPC are employed and solved simultaneously at each time interval. Each of these works at one compressor speed to find the optimum solutions for the other two inputs and the cost values. Then, the three cost values are compared to determine the minimum value, and their three corresponding inputs are used as the optimal solutions.

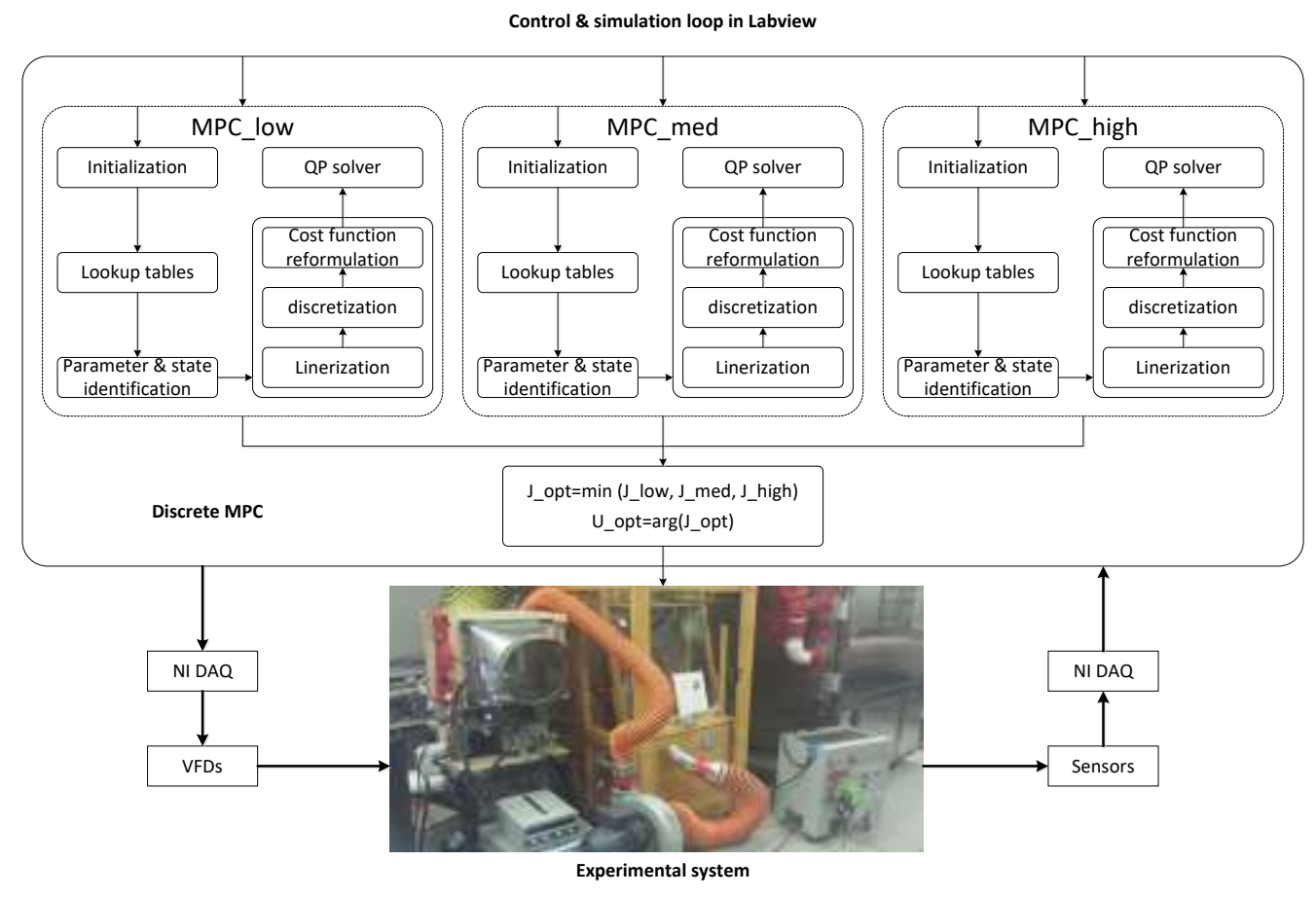

Fig. 8 Discrete MPC structure in LabVIEW

\section{CONTROLler Tuning AND PERFORMANCE COMPARISON}

In this section, the controller's performance is compared in terms of both controlled temperature performance and energy consumption. To study the A/C-R energy consumption at different ambient temperatures, the condenser is connected to an environmental chamber whose temperature is controlled. Three different ambient temperatures $\left[20^{\circ} \mathrm{C} ; 25^{\circ} \mathrm{C} ; 30^{\circ} \mathrm{C}\right]$ are chosen for the measure the temperature at different locations. For the experiments, an average temperature of 7 thermocouples closer to the air inlet of the condenser was used as the controlled temperature. The hysteresis band is an important parameter in the on/off controller, which should be determined before running the simulation. It decides the temperature oscillation and switching frequency of the whole cycle and subsequently, the wear condition of the compressor. Therefore, for the sake of a trade-off between the two aspects, $\pm 1^{\circ} \mathrm{C}$ is chosen as the band by the preliminary experiment study. Under different ambient temperature conditions, the A/C-R system runs at maximum capacity until the chamber temperature stabilizes. Three different temperatures 
Fig. 9 Temperature performance of on/off controller

\section{A. On/off Controller}

Table 1 Operating conditions and constraints of inputs and states

\begin{tabular}{ccccccccc}
\hline$T_{\text {amb }}\left({ }^{\circ} \mathrm{C}\right)$ & $T_{\text {cargo_init }}\left({ }^{\circ} \mathrm{C}\right)$ & $T_{\text {setpoint }}\left({ }^{\circ} \mathrm{C}\right)$ & $Q_{\text {door }}(\mathrm{kW})$ & $N_{\text {evap }}(\mathrm{Hz})$ & $N_{\text {cond }}(\mathrm{Hz})$ & $N_{\text {comp }}(\mathrm{rpm})$ & $P_{c}($ bar $)$ & $P_{e}($ bar $)$ \\
25 & 22.5 & 16 & 0.15 & {$[0 \sim 40]$} & {$[0 \sim 40]$} & {$\left[\begin{array}{l}2500 \\
3500 \\
4500\end{array}\right]$} & {$[0 \sim 17]$} & {$[0.7 \sim 7]$} \\
\hline
\end{tabular}

For the controller performance analysis, several experiments in different scenarios are performed. In order to demonstrate the performance of the controller, the test results under the operating condition mentioned in Table 1 are provided.

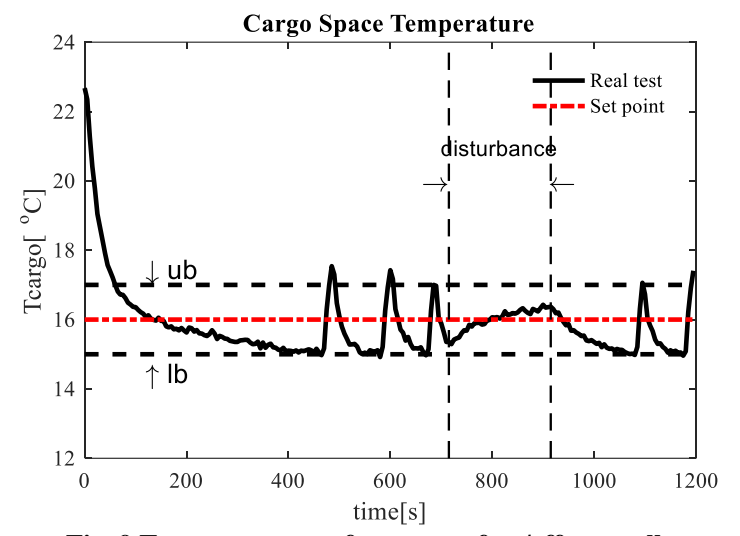

During the tests, an external disturbance of approximately $23 \%$ of the original heating load (the 200 -second disturbed region shown

91 in Fig. 9) was applied to the chamber to simulate the disturbance caused by an opening door.
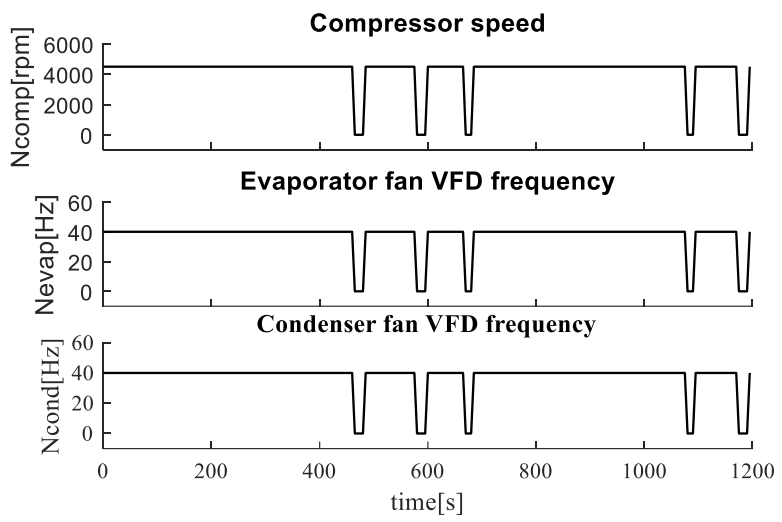

Fig. 10 System inputs of on/off controller

\section{B. Discrete $M P C$}

In this section, the controller parameters are briefly discussed and chosen. As the sample time $T_{s}$ decreases, the ability to reject disturbance improves, but the computational effort increases dramatically to guarantee the real-time application. Thus, the best choice is a trade-off between robustness and computational effort based on the dynamics of the system [33] [55]. The prediction horizon is related to the size of the quadratic optimization problem (the computational effort) and the accuracy of the prediction. A larger value leads to a better suboptimal solution with much more computational effort and increases the prediction's uncertainties. During the tuning process, $N$ starts with a small value until further increase cannot bring obvious impact on the controller's performance. From Table 1, the scale factors of the three inputs and the output can be set as 2000, 40, 40 and 10, respectively. In order to ensure the value of each term in the objective function in the same scale, a larger $Q$ is chosen. For the weight matrix $R$ of 
the control effort, a larger weight is selected for the compressor speed - the most energy-consuming component; whereas, the remaining values are zeros. Usually, the larger input rate weights of $S$ lead to more conservative control moves and produce a more robust performance [55]. By properly choosing a terminal weight from the Riccati equation, a finite-horizon MPC equivalent to an infinite-horizon linear quadratic regulator can be designed to achieve the close-loop stability of the plant [56][57]. If the applications involve constraints, it is difficult to find such a time-varying terminal weight, and it usually needs a terminal constraint to force the plant states into a defined region at the end of horizon [55]. However, as per the tuning guideline suggested in [43], a sufficiently large value of the terminal weight can lead to a better closed-loop performance in most cases. The controller's parameters are presented in Table 2.

Table 2 MPC parameter

\begin{tabular}{cccccc}
\hline$T_{s}(s)$ & $N$ & $Q$ & $R$ & $S$ & $P$ \\
\hline 5 & 10 & 100000 & {$\left[\begin{array}{lll}5 & 0 & 0 \\
0 & 0 & 0 \\
0 & 0 & 0\end{array}\right] \quad\left[\begin{array}{ccc}0 & 0 & 0 \\
0 & 1000 & 0 \\
0 & 0 & 1000\end{array}\right]$} & $1000 Q$ \\
\hline
\end{tabular}

Fig. 11 to Fig. 12 shows that the discrete MPC performs better than the on/off controller. For instance, the MPC controller can keep the temperature of the cargo in a smaller range, compared to $\pm 1^{\circ} \mathrm{C}$ of the on/off controller. With the external disturbances up to $23 \%$ of the original heating load, the controller will optimally increase the cold air flow rate to balance the extra heating using the evaporator fan to maintain the closed-loop dynamics.

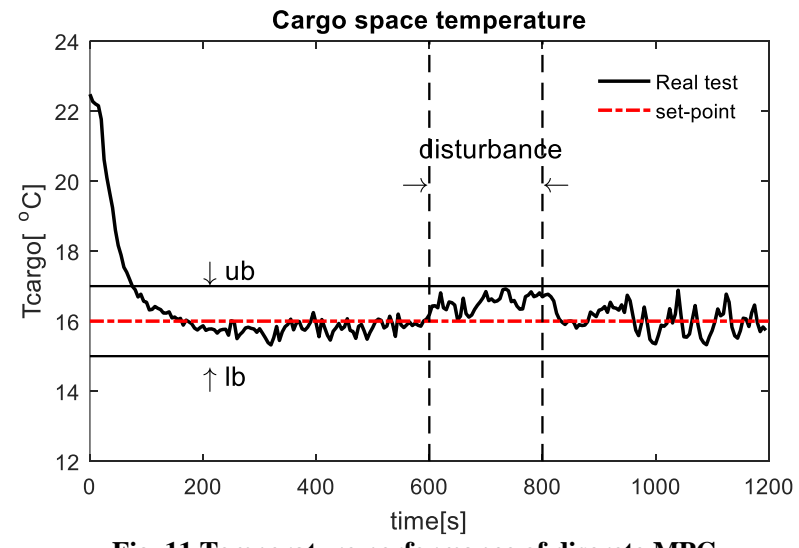

Fig. 11 Temperature performance of discrete MPC

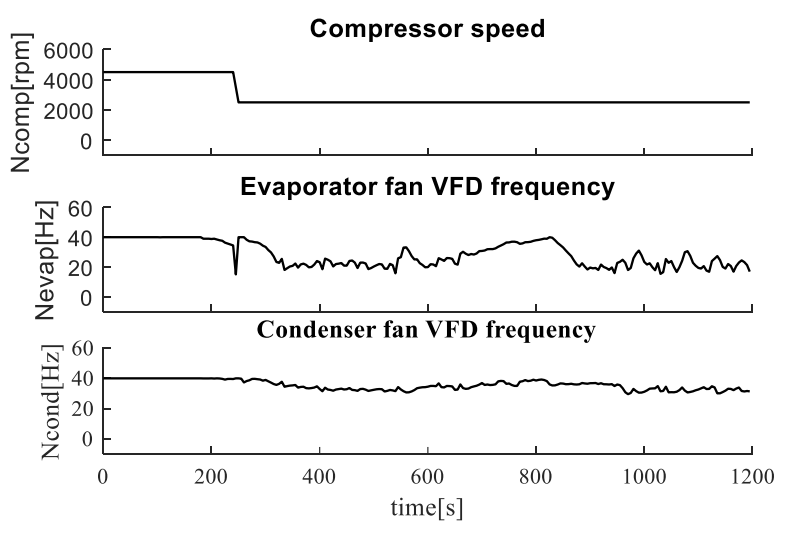

Fig. 12 System inputs of discrete MPC

314 As seen thus far, the MPC has better control performance than the conventional on/off controller because it is able to keep the 315 temperature around its set point with smaller oscillations. In addition, energy consumption serves as the most crucial criterion to 316 show the advantages of the MPC controller. In Table 3, the energy consumption in the 1200s under the same conditions for each 317 controller is given. As expected, the discrete MPC consumes less energy than the on/off controller under the examined scenario.

Table 3 Energy consumption of two controllers

\begin{tabular}{l|c|c} 
& Energy consumption for 1200s $($ Kwh $)$ & Improvement \\
\hline On/off & 0.2063 & basis \\
\hline Discrete MPC & 0.1902 & $7.8 \%$ \\
\hline
\end{tabular}


319 As mentioned above, a large disturbance is added to the plant and the results show good performance of the proposed controller. As 320 a common phenomenon of the A/C-R system, the frosting problem always exists [58]. When frost appears, it can cause model 321 inaccuracies. For example, the refrigerant mass flow rate through the valve will decrease when the system is frosting, and 322 accordingly, so do many other parameters such as pressures, temperature and superheat. In order to further demonstrate the 323 robustness of the developed controller, the experimental results during the thermostatic expansion valve (TXV) frosting under two 324 cases are presented. Fig. 13and Fig. 14 show the TXV with and without frost.

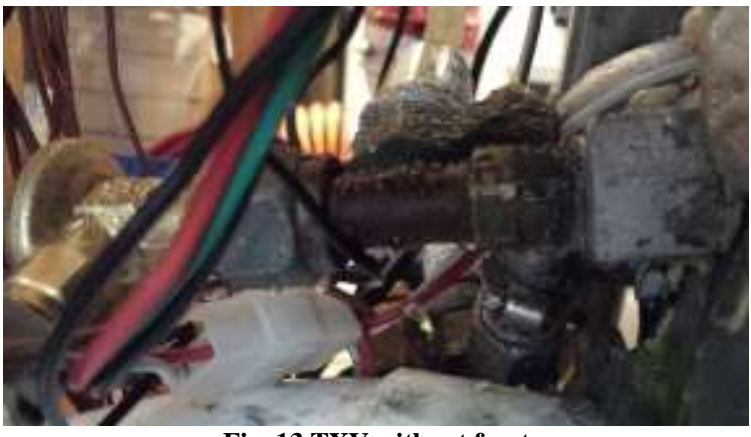

Fig. 13 TXV without frost

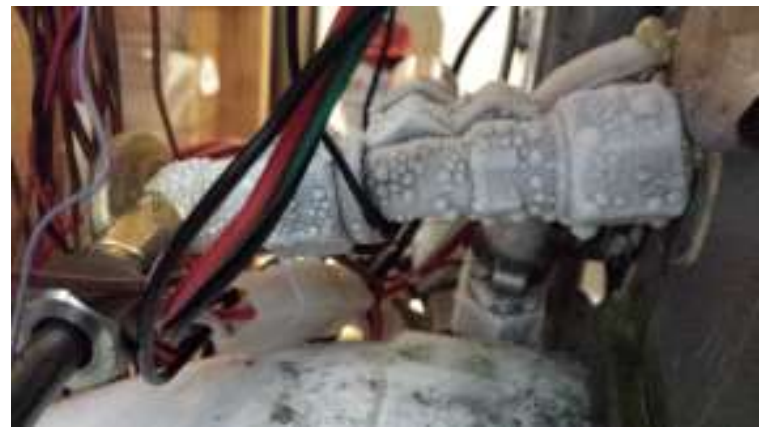

Fig. 14 TXV with frost

In the first scenario, the ambient temperature is $25^{\circ} \mathrm{C}$ and the temperature set point is $18^{\circ} \mathrm{C}$; whereas, the ambient temperature is set at $30^{\circ} \mathrm{C}$ with $16^{\circ} \mathrm{C}$ set point in the second scenario. The temperature responses and system inputs are demonstrated in Fig. 15 to Fig. 18, respectively. It can be seen from the figures that the closed-loop performance of this proposed MPC is still satisfactory under both large external disturbances and frosting conditions.

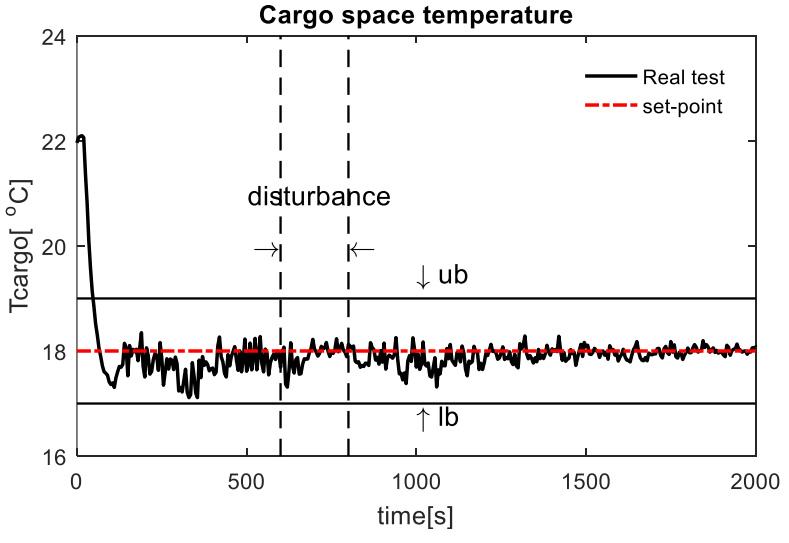

Fig. 15 Temperature performance of discrete MPC under first scenario

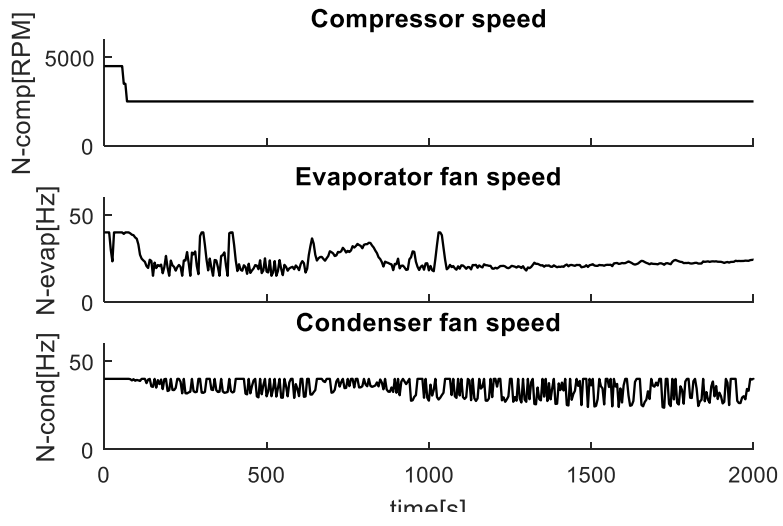

Fig. 16 System inputs of discrete MPC under first scenario 


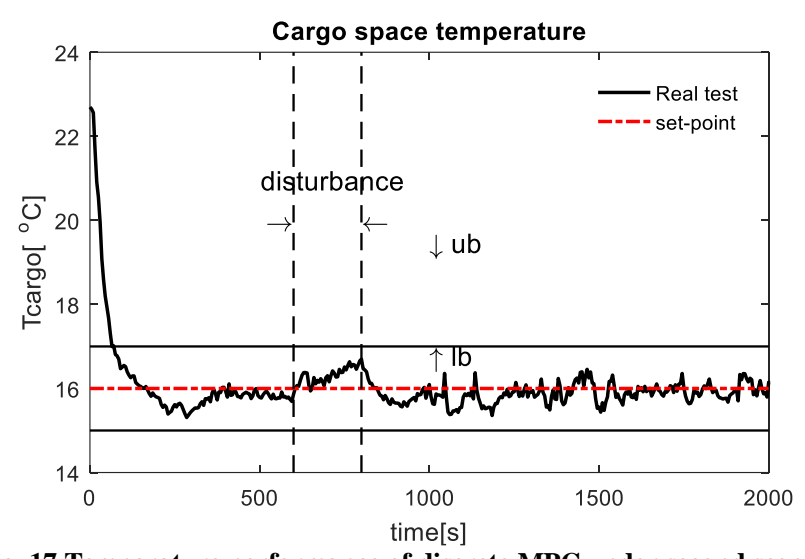

Fig. 17 Temperature performance of discrete MPC under second scenario

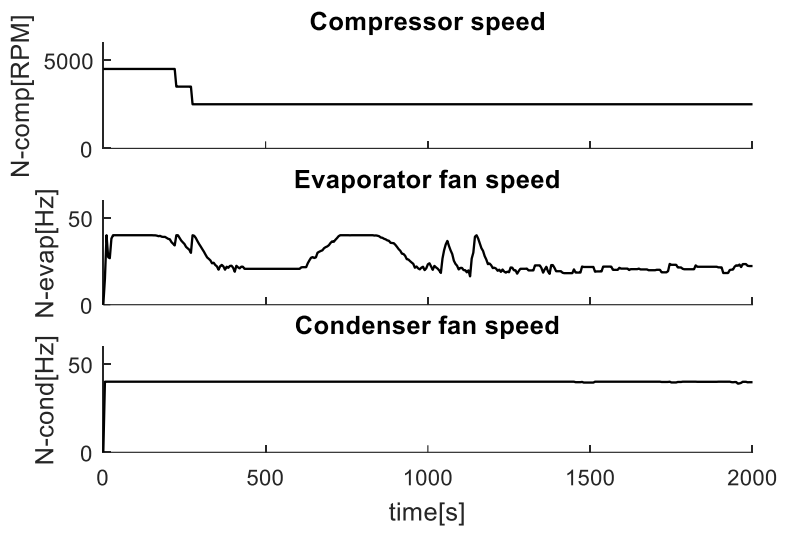

Fig. 18 System inputs of discrete MPC under second scenario

\section{CASE STUDY}

In this last section, the controller's performance and energy-saving benefits are studied under one fixed heating load condition, so in this section, the performance of both controllers are simulated under a time-varying heating load condition. Table 4 shows the energy consumptions of the on/off controller and the discrete MPC under different heating loads. It can be seen that under higher heating load (above $0.5 \mathrm{~kW}$ ) conditions, the discrete MPC consumes less energy than the on/off controller while for lower heating loads, the on/off controller is more efficient. Thus, it cannot be concluded that the discrete MPC is better than the on/off controller, rather than the discrete MPC could alleviate temperature fluctuations. That is why the other controllers appear in the following sections.

\begin{tabular}{|c|c|c|}
\hline \multirow{2}{*}{ Heating load $(k W)$} & \multicolumn{2}{|c|}{ Energy consumption for 1200s $(K w h)$} \\
\hline & On/off & Discrete MPC \\
\hline 0.8 & 0.2311 & 0.2119 \\
\hline 0.7 & 0.2162 & 0.1955 \\
\hline 0.6 & 0.1895 & 0.1789 \\
\hline 0.5 & 0.1671 & 0.1657 \\
\hline 0.4 & 0.1451 & 0.1624 \\
\hline 0.3 & 0.1179 & 0.1523 \\
\hline 0.2 & 0.0925 & 0.1343 \\
\hline
\end{tabular}

\section{A. Hybrid controllers}

By studying the energy consumptions under different heating load scenarios in Table 4, a direct hybrid controller could be intuitively designed by combining the discrete MPC and the on/off controller along with an identifier that could estimate the current heating load. The criterion for activating the discrete MPC is when the heating load is higher than $0.5 \mathrm{~kW}$, and the on/off controller is activated in all other scenarios. Based on the experimental and simulated data, it is known that the cooling capacity produced by the system using the minimum compressor speed can balance the heating load under $0.5 \mathrm{~kW}$. In addition, the compressor is the most energy-consuming component in A/C-R system. As a result, the minimum compressor speed and maximum evaporator and condenser fan speeds are used in this on/off controller. 
alleviate the effects of this phenomenon, an adaptive hybrid controller is given. The main idea is that the system starts working by using the discrete MPC until the controlled temperature settles down at its set point. Then, the MPC is still used as long as the current heating load is over $0.5 \mathrm{~kW}$. Otherwise, the on/off controller will be used. In addition, the speed of the evaporator fan will be updated by:

$$
N_{\text {evap }}=N_{\text {evap-mpc }}+k_{\text {evap }}\left(T_{\text {evap-cham }}-T_{\text {setpoint }}\right)
$$

where, $N_{\text {evap-mpc }}$, is the speed found by the discrete MPC at the switching point; $k_{\text {evap }}$, is a proportional coefficient and related to MPC. Otherwise, when it is high enough, it will become the direct hybrid controller.

\section{B. Continuous MPC}

In some recent applications of the A/C-R system, the continuous variable components instead of components with several different speeds are employed. In order to study the potential of the MPC in these cases, a continuous MPC is designed based on the same model and procedures shown above. In this controller, the input of the compressor speed can continuously change from zero to its maximum speed [59].

\section{Controllers Comparison}

In order to compare the controllers discussed above, a heating load cycle shown in Fig. 19 is applied to the system for the simulations. This cycle is used to represent the heating load during a day in 1200 seconds. As is well-known, the temperature at noon is higher than that in the morning and evening; as such, the heating load applied to the chamber reflects daily temperature robustness of the controllers.

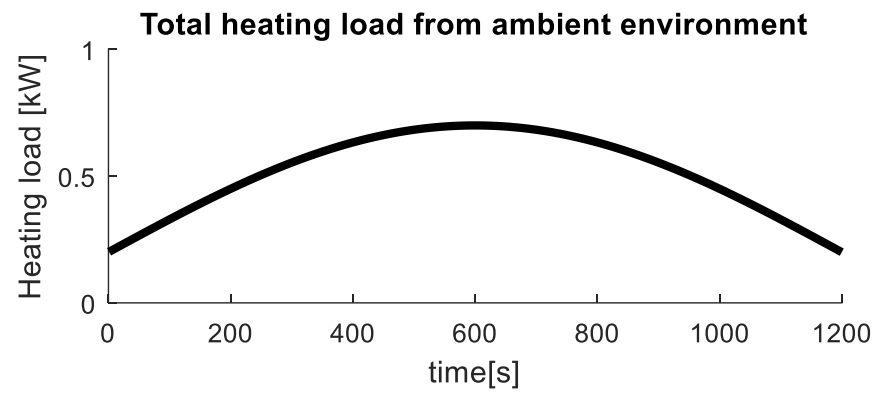

Fig. 19 A heating load pattern

Fig. 20 shows the system inputs of the on/off controller. The system stays on for a longer period of time under the large heating load consumption will be also used as a basis of comparison for the following controllers. 


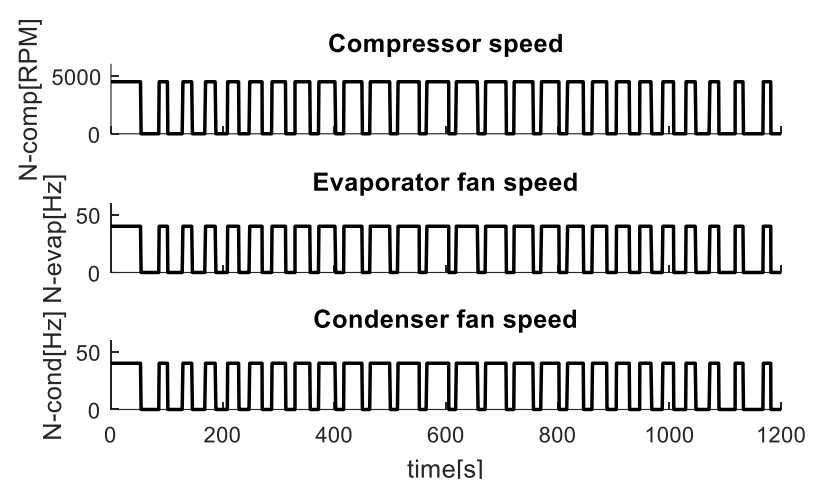

Fig. 20 System inputs of on/off controller

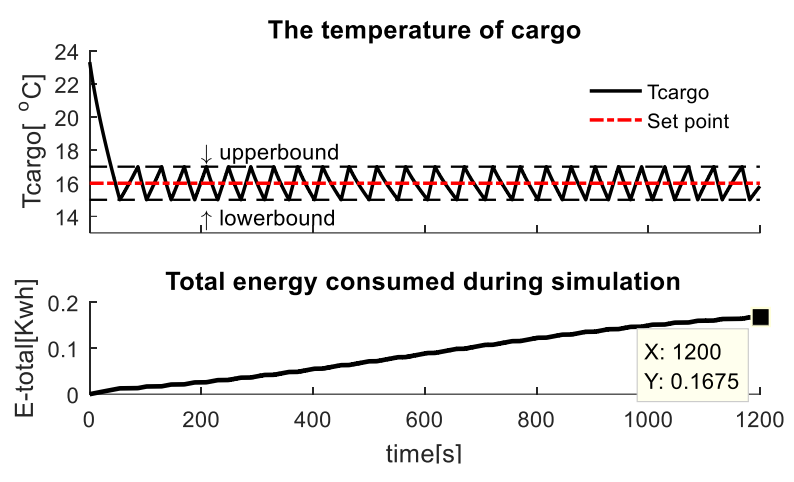

Fig. 21 Temperature performance and energy consumption

The system inputs, temperature behavior and energy consumption for the discrete MPC are provided by Fig. 22 and Fig. 23.

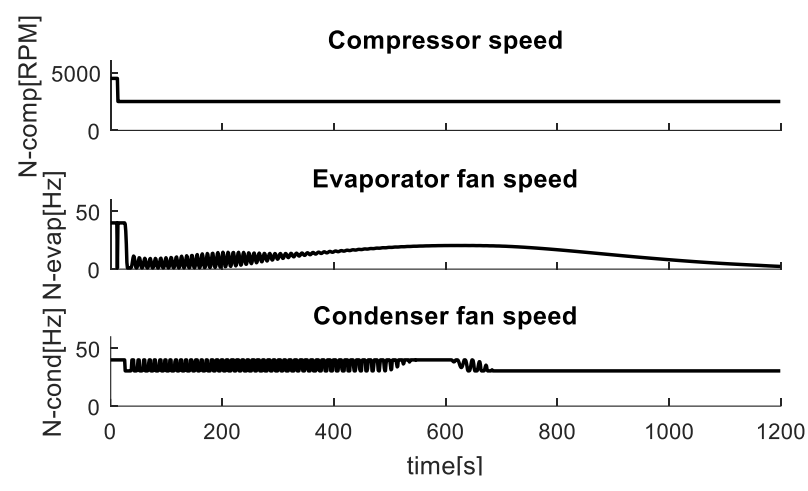

Fig. 22 System inputs of discrete MPC

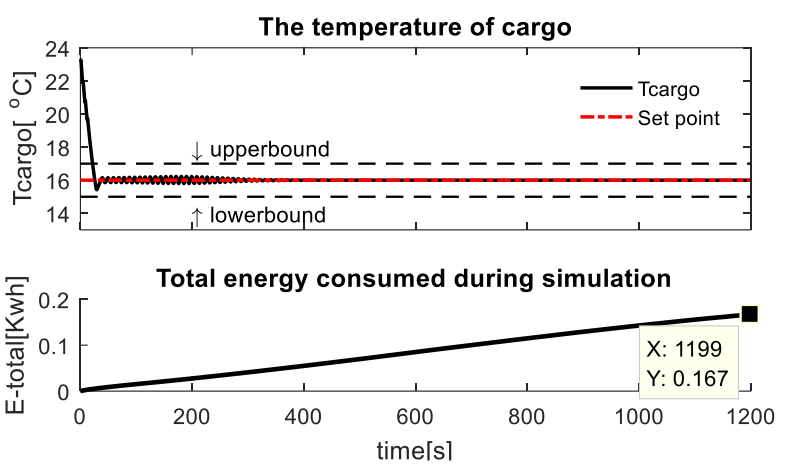

Fig. 23 Temperature performance and energy consumption

369 The results of the direct hybrid controller are shown in Fig. 24 and Fig. 25. It can be seen that the on/off controller and the discrete $370 \quad$ MPC are alternated when the heating load is $0.5 \mathrm{~kW}$.

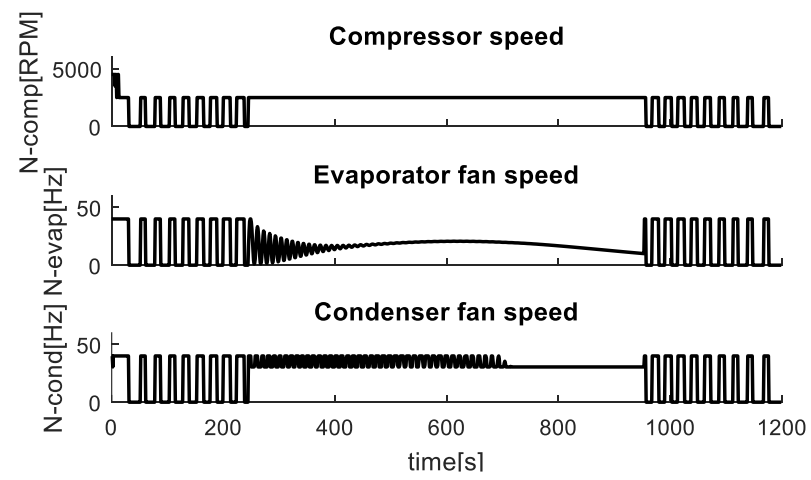

Fig. 24 System inputs of direct hybrid controller

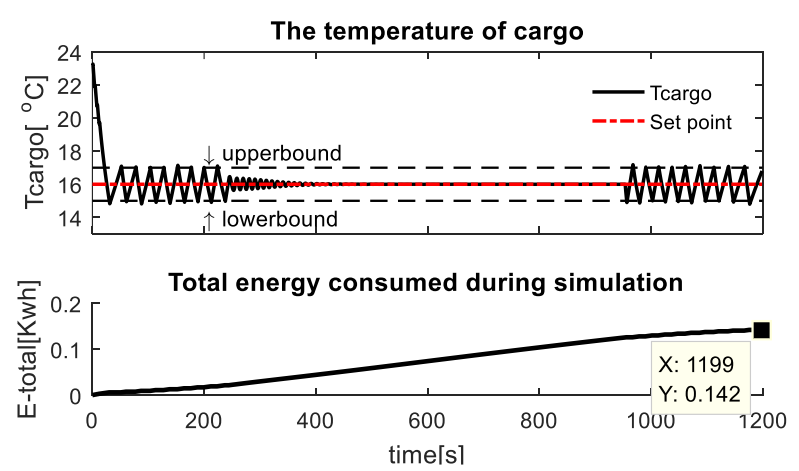

Fig. 25 Temperature performance and energy consumption

371 By choosing 1 as the value of $k_{\text {evap }}$, the results of the adaptive hybrid controller are given in Fig. 26 and Fig. 27. These figures

372 show that in comparison to the direct hybrid controller, the lower activation frequency of the system is obtained at the expense of energy consumption. As a result, a trade-off performance between energy consumption and switching frequency of the system can

374 be obtained by using the desired value of $k_{\text {evap }}$. 


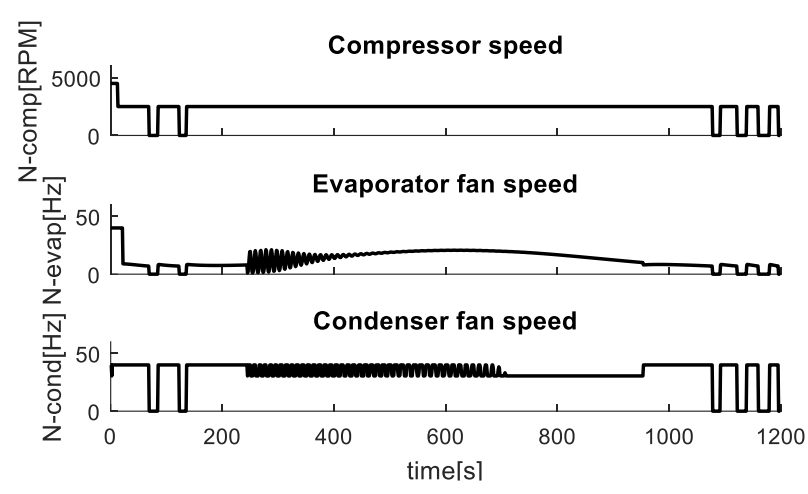

Fig. 26 System inputs of adaptive hybrid controller

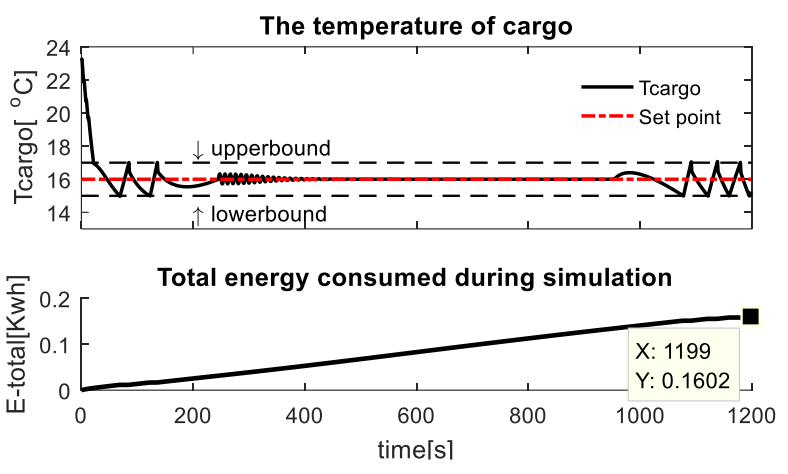

Fig. 27 Temperature performance and energy consumption

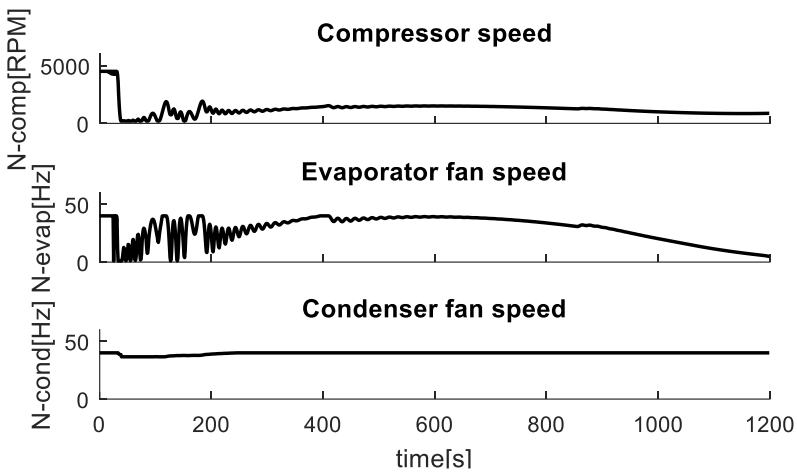

Fig. 28 System inputs of continuous MPC

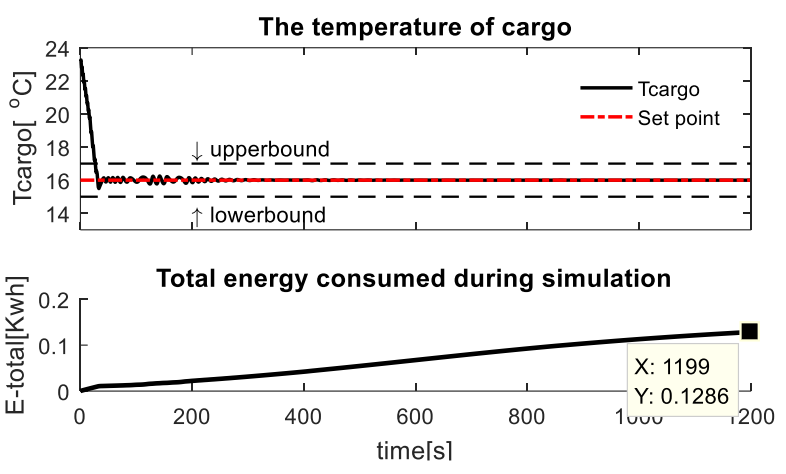

Fig. 29 Temperature performance and energy consumption

All the above simulations are done under the same working conditions as given in Table 1 but with the new heating load cycle shown in Fig. 19. The total energy consumption and improvements of the proposed controllers with respect to the conventional on/off controller are listed in Table 5.

Table 5 Energy consumptions of different controllers

\begin{tabular}{lcc}
\hline Controllers & Energy consumption 1200s (Kwh) & Improvement (\%) \\
\hline On/off & 0.1675 & Basis \\
\hline Discrete MPC & 0.1670 & 0.24 \\
\hline Direct hybrid & 0.1420 & 15.17 \\
\hline Adaptive hybrid & 0.1602 & 4.30 \\
\hline Continuous MPC & 0.1286 & 23.18 \\
\hline
\end{tabular}

383 The goal of this study was to develop an advanced controller for automotive A/C-R systems, which can not only save energy but 384 also enhance performance.

385 In this study, a control-based model was proposed and validated by an experimental A/C-R system used in trucks. Then, an 386 on/off controller was designed as a benchmark to demonstrate the improvement of other controllers. Due to the existence of the 
controller development is accurate and the discrete MPC not only consumes less energy but also has better temperature behavior than the on/off controller under the examined condition. The robustness of the proposed MPC was also evaluated with the appearance of large external disturbances and the conditions of the plant frosting period. All the test results showed that the MPC is robust. Then, the controller was tested under the time-varying heating load condition. The results also indicated that the discrete MPC uses less energy only under higher heating load conditions. That is why the two hybrid controllers were studied and developed. The direct hybrid combines the energy-saving advantage of the discrete MPC and the on/off controller under all conditions; whereas, the adaptive hybrid controller can reach a balance between energy consumption and component wear. These hybrid controllers are two promising options for the A/C-R systems with discrete inputs according to the requirements. The continuous MPC was also examined, which is the optimal controller for the A/C-R systems with continuously varying components because it can save up to $23 \%$ energy with a satisfactory performance.

In addition, the simulation and experimental analysis demonstrated that the proposed MPCs can be used in real time, and it can also achieve the goals of saving energy and improving performance. Therefore, the developing process and modeling method of the MPC can be applied to other complex plants. Future studies will focus on integrating the power consumption model of the whole system into the objective function instead of only control efforts, designing a fully controllable experimental system to test the proposed continuous MPC controller, and implementing the controller into a real vehicle to test its performance in practice.

\section{ACKNOWLEDGEMENTS}

The authors would like to acknowledge the financial support of Automotive Partnership Canada (APC) and the financial and technical support of Cool-it Group.

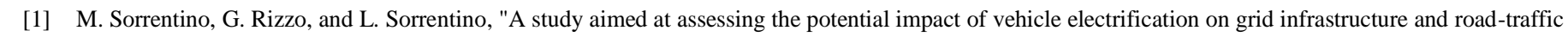
greenhouse emissions," Applied Energy, vol. 120, pp. 31-40, May 2014.

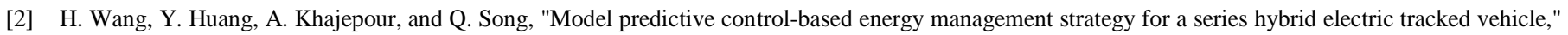
Applied Energy, vol. 182, pp. 105-114, Nov. 2016.

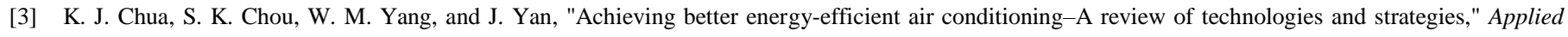
Energy, vol. 104, pp. 87-104, Apr. 2013.

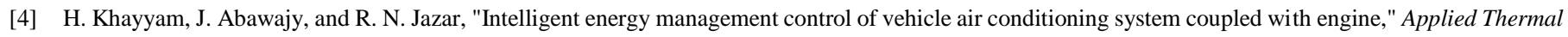
Engineering, vol. 48, pp. 211-224, Dec. 2012.

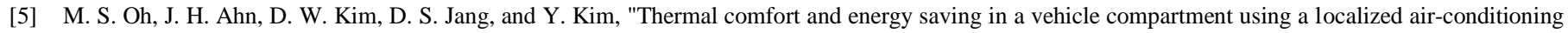
system," Applied Energy, vol. 133, pp. 14-21, Nov. 2014.

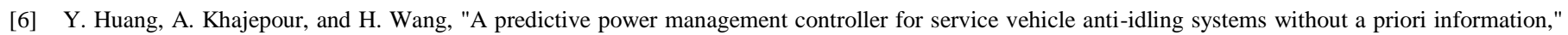
Applied Energy, vol. 182, pp. 548-557, Nov. 2016. 
[7] X. Hu, L. Johannesson, N. Murgovski, and B. Egardt, "Longevity-conscious dimensioning and power management of the hybrid energy storage system in a fuel cell hybrid electric bus," Applied Energy, vol. 137, pp. 913-924, Jan. 2015.

[8] F. Sun, X. Hu, Y. Zou, and S. Li, "Adaptive unscented Kalman filtering for state of charge estimation of a lithium-ion battery for electric vehicles," Energy, vol. 36, no. 5, pp. 3531-3540, May 2011.

[9] X. Hu, S. E. Li, Z. Jia, and B. Egardt, "Enhanced sample entropy-based health management of Li-ion battery for electrified vehicles," Energy, vol. 64, pp. 953-960, Jan. 2014.

[10] H. Budde-Meiwes et al., "A review of current automotive battery technology and future prospects," Proceedings of the Institution of Mechanical Engineers, Part D: Journal of Automobile Engineering, vol. 227, no. 5, pp. 761-776, Apr. 2013.

[11] Y. Huang, A. Khajepour, F. Bagheri, and M. Bahrami, "Modelling and optimal energy-saving control of automotive air-conditioning and refrigeration systems," Proceedings of the Institution of Mechanical Engineers, Part D: Journal of Automobile Engineering, Mar. 2016.

[12] A. Leva, L. Piroddi, M. Di Felice, A. Boer, and R. Paganini, "Adaptive relay-based control of household freezers with on-off actuators," Control Engineering Practice, vol. 18, no. 1, pp. 94-102, Jan. 2010.

[13] B. Li, R. Otten, V. Chandan, W. F. Mohs, J. Berge, and A. G. Alleyne, "Optimal on-off control of refrigerated transport systems," Control Engineering Practice, vol. 18, no. 12, pp. 1406-1417, Dec. 2010.

[14] J. Liu, H. Zhou and X. Zhou, "Automotive air conditioning control- A survey," International Conference on Electronic \& Mechanical Engineering and Information Technology, EMEIT 2011, Harbin, Heilongjiang, China, 2011.

[15] G. Høgh and R. Nielsen, "Model Based Nonlinear Control of Refrigeration Systems," M.S. Thesis, Section for Automation and Control, Aalborg University, DK - 9100 Aalborg, Denmark, 2008.

[16] A. Afram and F. Janabi-Sharifi, "Theory and applications of HVAC control systems - A review of model predictive control (MPC)," Building and Environment, vol. 72, pp. 343-355, Feb. 2014.

[17] Petersen, A. and Lund, P., "Modeling and Control of Refrigeration Systems," M.S. Thesis, Institute of Electronic systems, Aalborg University, DK - 9100 Aalborg, Denmark, 2004.

[18] N. Li, L. Xia, D. Shiming, X. Xu, and M.-Y. Chan, "Dynamic modeling and control of a direct expansion air conditioning system using artificial neural network," Applied Energy, vol. 91, no. 1, pp. 290-300, Mar. 2012.

[19] M. Mohanraj, S. Jayaraj, and C. Muraleedharan, "Applications of artificial neural networks for refrigeration, air-conditioning and heat pump systems-A review," Renewable and Sustainable Energy Reviews, vol. 16, no. 2, pp. 1340-1358, Feb. 2012.

[20] Koo, B., Yoo, Y. and Won, S., (2012), October. Super-twisting algorithm-based sliding mode controller for a refrigeration system. In Control, Automation and Systems (ICCAS), 2012 12th International Conference on (pp. 34-38). IEEE.

[21] Shah, R., Alleyne, A.G., Bullard, C.W., Rasmussen, B.P. and Hrnjak, P.S., (2003). Dynamic modeling and control of single and multi-evaporator subcritical vapor compression systems. Air Conditioning and Refrigeration Center. College of Engineering. University of Illinois at Urbana-Champaign.

[22] Rasmussen, B.P. and Alleyne, A.G., (2006). Dynamic modeling and advanced control of air conditioning and refrigeration systems. Air Conditioning and Refrigeration Center. College of Engineering. University of Illinois at Urbana-Champaign.

[23] He XD. Dynamic Modeling and Multivariable control of Vapor Compression Cycles in Air Conditioning Systems. PhD thesis, Massachusetts Institute of Technology, USA, 1996.

[24] X.-D. He, S. Liu, H. Asada, and H. Itoh, "Multivariable control of vapor compression systems," HVAC\&R Research, vol. 4, no. 3, pp. $205-230$, Jul. 1998.

[25] Larsen, L.F.S., (2006). Model based control of refrigeration systems. PhD thesis Department of Control Engineering, Aalborg University, DK - 9100 Aalborg, Denmark. 
[26] J. M. Sousa, R. Babuška, and H. B. Verbruggen, "Fuzzy predictive control applied to an air-conditioning system," Control Engineering Practice, vol. 5, no. 10, pp. 1395-1406, Oct. 1997.

[27] M. HE, W. CAI, and S. LI, "Multiple fuzzy model-based temperature predictive control for HVAC systems," Information Sciences, vol. 169, no. 1-2, pp. 155174, Jan. 2005.

[28] Razi, M., Farrokhi, M. and Saeidi, M.H., (2006). April. Neuro-predictive control for automotive air conditioning system. In Engineering of Intelligent Systems, IEEE International Conference on (pp. 1-6). IEEE.

[29] Elliott, M.S. and Rasmussen, B.P., (2008). Model-based predictive control of a multi-evaporator vapor compression cooling cycle. In American Control Conference, (pp. 1463-1468). IEEE.

[30] G. Huang and A. L. Dexter, "Realization of robust nonlinear model predictive control by offline optimisation," Journal of Process Control, vol. 18, no. 5, pp. 431-438, Jun. 2008.

[31] Jain, N. and Alleyne, A.G., (2011). June. Thermodynamics-based optimization and control of vapor-compression cycle operation: optimization criteria. In American Control Conference (ACC), 2011 (pp. 1352-1357). IEEE.

[32] Ma, J., Qin, J., Salsbury, T. and Xu, P., (2012). Demand reduction in building energy systems based on economic model predictive control. Chemical Engineering Science, 67(1), pp.92-100.

[33] Gustavsson, A., (2012). Dynamic modeling and Model Predictive Control of a vapor compression system. PhD thesis, Department of Electrical Engineering, Automatic Control. Linköping University, The Institute of Technology, Linköping University,

[34] Hovgard, T.G., Larsen, L.F., Bagterp, J. and Boyd, J.S., (2012). Fast nonconvex model predictive control for commercial refrigeration. https://stanford.edu/ boyd/papers/pdf/noncvx_mpc_refr_nmpc.pdf.

[35] Yudong, F. Borrelli, B. Hencey, B. Coffey, S. Bengea, and P. Haves, "Model predictive control for the operation of building cooling systems," IEEE Transactions on Control Systems Technology, vol. 20, no. 3, pp. 796-803, May 2012.

[36] F. Blanchin and W. Ukovich, "Linear programming approach to the control of discrete-time periodic systems with uncertain inputs," Journal of Optimization Theory and Applications, vol. 78, no. 3, pp. 523-539, Sep. 1993.

[37] A. Aswani, N. Master, J. Taneja, D. Culler, and C. Tomlin, "Reducing transient and steady state electricity consumption in HVAC using learning-based model-predictive control," Proceedings of the IEEE, vol. 100, no. 1, pp. 240-253, Jan. 2012.

[38] M. S. Elliott and B. P. Rasmussen, "Decentralized model predictive control of a multi-evaporator air conditioning system," Control Engineering Practice, vol. 21, no. 12, pp. 1665-1677, Dec. 2013.

[39] K. K. Sørensen, J. Stoustrup, and T. Bak, "Adaptive MPC for a reefer container," Control Engineering Practice, vol. 44, pp. 55-64, Nov. 2015.

[40] D. Sarabia, F. Capraro, L. F. S. Larsen, and C. de Prada, "Hybrid NMPC of supermarket display cases," Control Engineering Practice, vol. 17, no. 4, pp. 428441, Apr. 2009.

[41] C. Sonntag, (2009). Control of a supermarket refrigeration system, HYCON WP4b/WP2, Department of Biochemical and Chemical Engineering Process Dynamics and Operations Group (DYN), HYCON Workshop Brussels.

[42] Patel, T., Shah, J. and Satria, M., (2013). Dynamic Modeling, Optimal Control Design and Comparison between various control schemes of Home Refrigerator.

[43] L. Fagiano and A. R. Teel, "Generalized terminal state constraint for model predictive control," Automatica, vol. 49, no. 9, pp. 2622-2631, Sep. 2013.

[44] Fagiano, L. and Teel, A.R., (2013). On generalized terminal state constraints for model predictive control, http://arxiv.org/abs/1207.0788v2.

[45] B. P. Rasmussen and A. G. Alleyne, "Control-oriented modeling of Transcritical vapor compression systems," Journal of Dynamic Systems, Measurement, and Control, vol. 126, no. 1, p. 54, 2004. 
[46] Eldredge, B.D. and Alleyne, A.G., (2006). Improving the Accuracy and Scope of Control-Oriented Vapor Compression Cycle System Models. Air Conditioning and Refrigeration Center. College of Engineering. University of Illinois at Urbana-Champaign.

[47] D. Zhao and G. Tan, "Numerical analysis of a shell-and-tube latent heat storage unit with fins for air-conditioning application," Applied Energy, vol. 138, pp. 381-392, Jan. 2015.

[48] T. L. McKinley and A. G. Alleyne, "An advanced nonlinear switched heat exchanger model for vapor compression cycles using the moving-boundary method," International Journal of Refrigeration, vol. 31, no. 7, pp. 1253-1264, Nov. 2008.

[49] Li, B. (2009). Dynamic modeling and control of vapor compression cycle systems with shut-down and start-up operations. MASc thesis, Air Conditioning and Refrigeration Center, College of Engineering, University of Illinois at Urbana-Champaign.

[50] L. Serrao, S. Onori, and G. Rizzoni, "A comparative analysis of energy management strategies for hybrid electric vehicles," Journal of Dynamic Systems, Measurement, and Control, vol. 133, no. 3, p. 031012, 2011.

[51] L. Grüne and J. Pannek, Nonlinear Model Predictive Control-Theory and algorithms. @ Springer-Verlag London Limited, 2011.

[52] Y. Huang, “Anti-Idling Systems for Service Vehicles with A/C-R Units: Modeling, Holistic Control, and Experiments”, Ph.D. Thesis, Mechanical and Mechatronics Department, University of Waterloo, ON. Canada, 2016.

[53] Borrelli F., Bemporad A. and Morari M. (2014). Predictive Control for linear and hybrid systems. control.ee.ethz.ch/ stdavid/BBMbook_Cambridge_newstyle.pdf.

[54] H. J. Ferreau, C. Kirches, A. Potschka, H. G. Bock, and M. Diehl, "QpOASES: A parametric active-set algorithm for quadratic programming," Mathematical Programming Computation, vol. 6, no. 4, pp. 327-363, Apr. 2014.

[55] Bemporad, A., Morari, M. and Ricker, N.L., (2010). Model Predictive Control Toolbox 3 User's Guide. The mathworks.

[56] P. O. M. Scokaert and J. B. Rawlings, "Constrained linear quadratic regulation," IEEE Transactions on Automatic Control, vol. 43, no. 8, pp. 1163-1169, 1998.

[57] Jain, N., Burns, D.J., Di Cairano, S., Laughman, C.R. and Bortoff, S.A., (2014). Model Predictive Control of Variable Refrigerant Flow Systems. The International Refrigeration and Air Conditioning Conference.

[58] C. Tian, X. Li, and X. Yang, "Numerical analysis of evaporator frosting in automotive air-conditioning system with a variable-displacement compressor," Applied Energy, vol. 82, no. 1, pp. 1-22, Sep. 2005.

[59] Y. Huang, A. Khajepour, M. Khazraee, M. Bahrami, "A Comparative Study of the Energy-saving Controllers for Automotive Air-conditioning/Refrigeration Systems," Journal of Dynamic Systems, Measurement, and Control. 2016. 